\title{
Ordered Mesoporous Silicas and Carbons with Large Accessible Pores Templated from Amphiphilic Diblock Copolymer Poly(ethylene oxide)-b-Polystyrene
}

Yonghui Deng, Ting Yu, Ying Wan, Yifeng Shi, Yan Meng, Dong Gu, Lijuan Zhang, Yan Huang, Chong Liu, Xiaojing Wu and Dongyuan Zhao* 


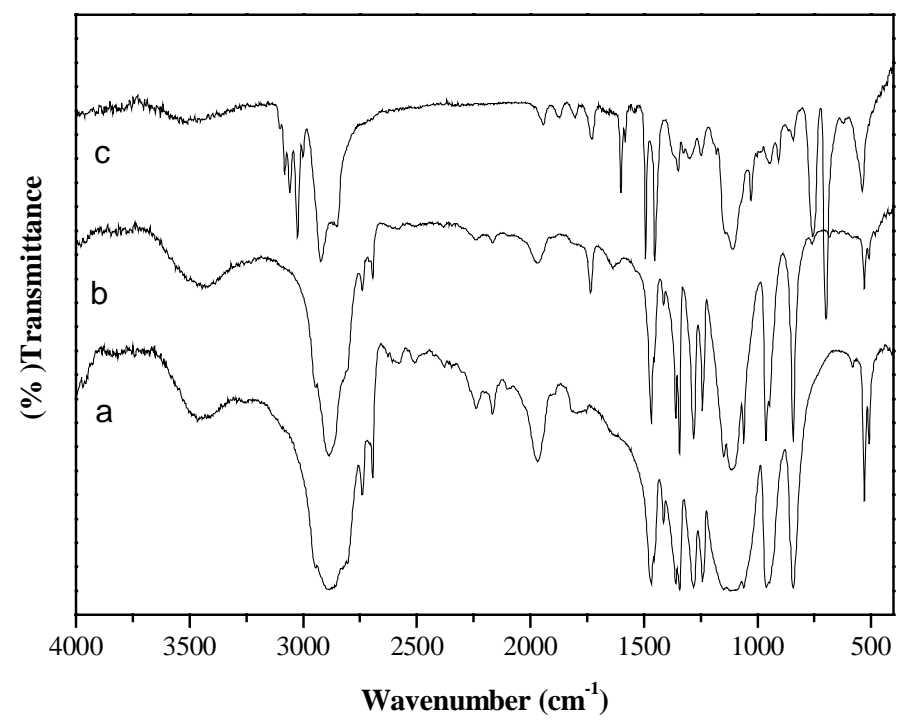

Figure S1. FT-IR spectra of PEO5000 (a), PEO-Br (M1) (b) and PEO-b-PS (M2) (c), in which the ether stretch appears at $1109 \mathrm{~cm}^{-1}$ in PEO precursor, macroinitiator PEO-Br (M1) and diblock copolymer PEO- $b$-PS (M2). After the acetylation reaction, a carbonyl stretch occurs at $1734 \mathrm{~cm}^{-1}$ in PEO-Br. The bands at 3100-3000, 1602 and $700 \mathrm{~cm}^{-1}$ illustrate the presence of PS block in the PEO- $b$-PS diblock copolymer after the polymerization of styrene.
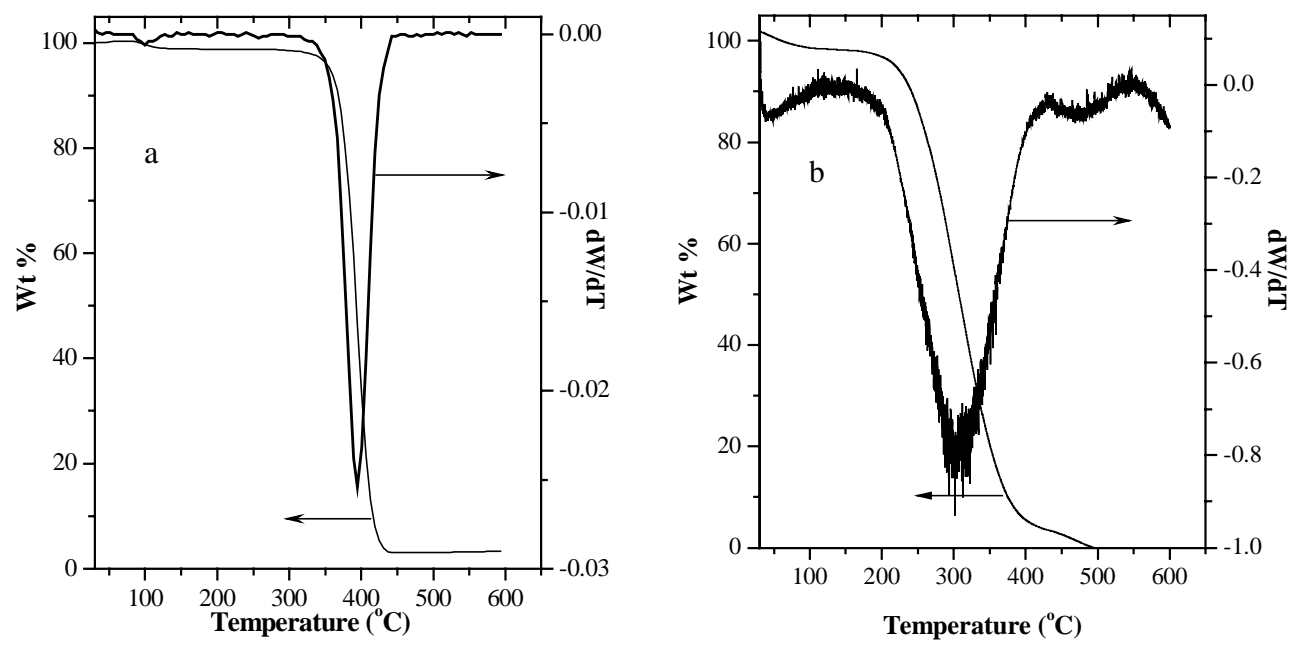

Figure S2. TGA and DTG curves of $\mathrm{PEO}_{125} \mathrm{PS}_{230}$ diblock polymer conducted (a) in $\mathrm{N}_{2}$ and (b) in air, respectively, suggesting that PEO-b-PS can be fully decomposed in $\mathrm{N}_{2}$ at $\sim 410^{\circ} \mathrm{C}$ and in air at $\sim 300^{\circ} \mathrm{C}$. 


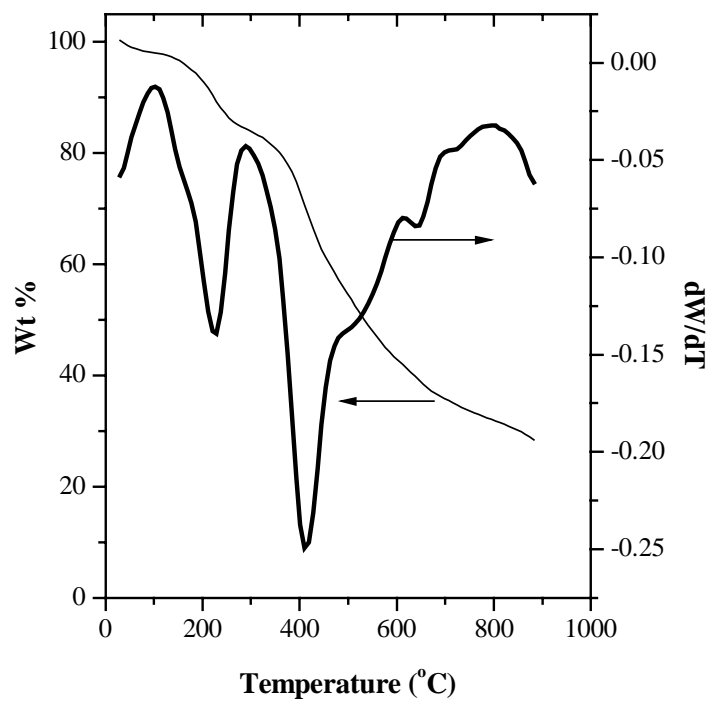

Figure S3. TGA and DTG curves of PEO- $b$-PS/resols composites (as-made C-FDU-18). The measurement was carried out under $\mathrm{N}_{2}$ with a heating rate of $5^{\circ} \mathrm{C} / \mathrm{min}$.

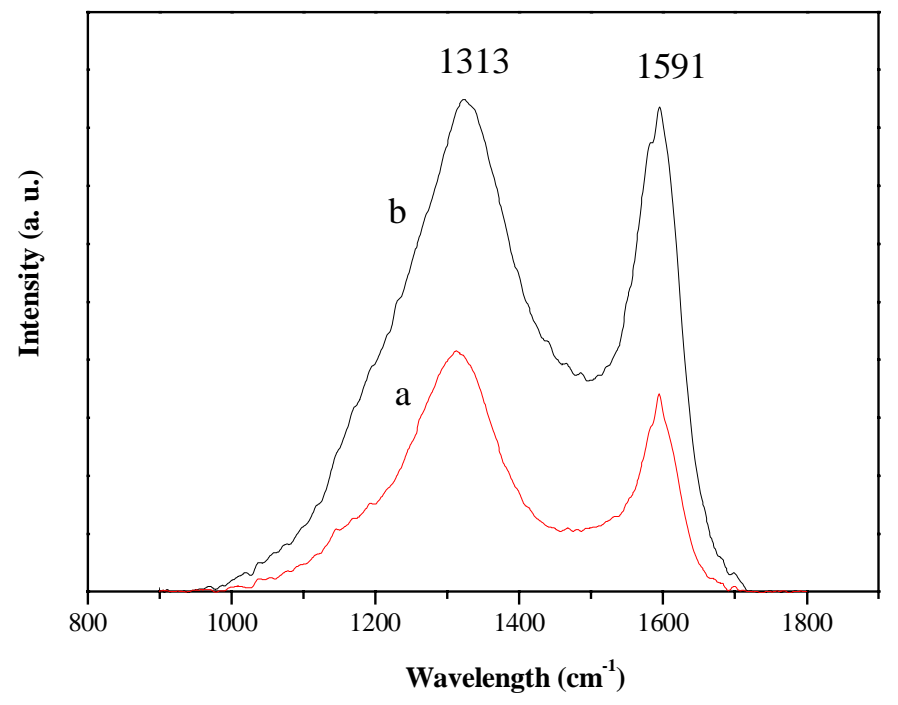

Figure S4. Raman spectra of C-FDU-18-800 (a) and C-FDU-18-900 (b), showing G band at 1591 $\mathrm{cm}^{-1}$ and $\mathrm{D}$ band at $1313 \mathrm{~cm}^{-1}$. It suggests that the obtained highly ordered mesoporous carbons have a low degree of graphitization. 


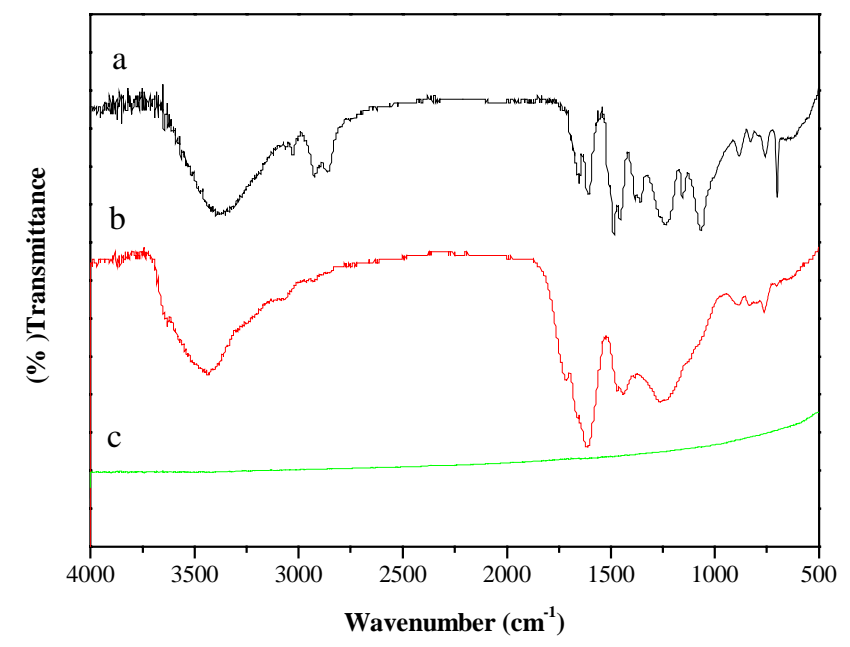

Figure S5. FT-IR spectra of as-made C-FDU-18 (a), C-FDU-18-450 (b) and C-FDU-18-800 (c). For curve a, the strong and broad band at $3400 \mathrm{~cm}^{-1}$ is associated with the phenolic $-\mathrm{OH}$ groups, and the bands at 1100 and $2800 \mathrm{~cm}^{-1}$ are assigned to PEO- $b$-PS. The disappearance of characteristic peaks at $1109 \mathrm{~cm}^{-1}$ associated with PEO block and at 2850-2930 $\mathrm{cm}^{-1}$ with PS block in curve b suggests the removal of PEO- $b$-PS template by calcination in $\mathrm{N}_{2}$. For curve $c$, no adsorption was observed, suggesting almost complete removal of $\mathrm{H}$ and $\mathrm{O}$ by pyrolysis at higher temperature.

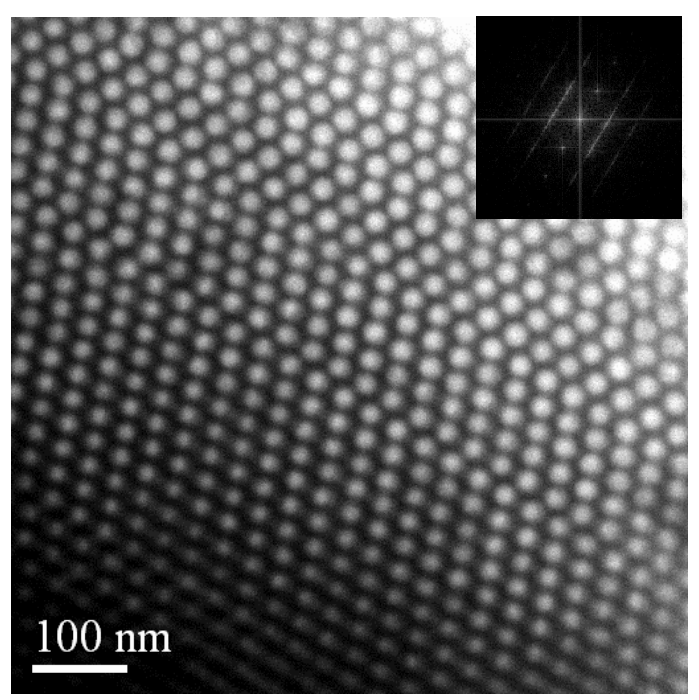

Figure S6. TEM image of Si-FDU-18-HC obtained with hydrothermal treatment, indicating a distorted minor domain of fcc structure viewed from the [110] direction. 


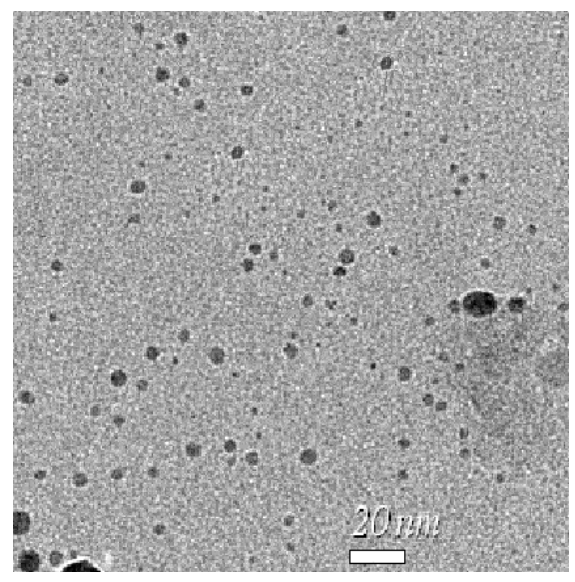

Figure S7. TEM image of carbon nanoparticles obtained after etching silica framework of Si-FDU-18-C with hydrofluoric acid solution.
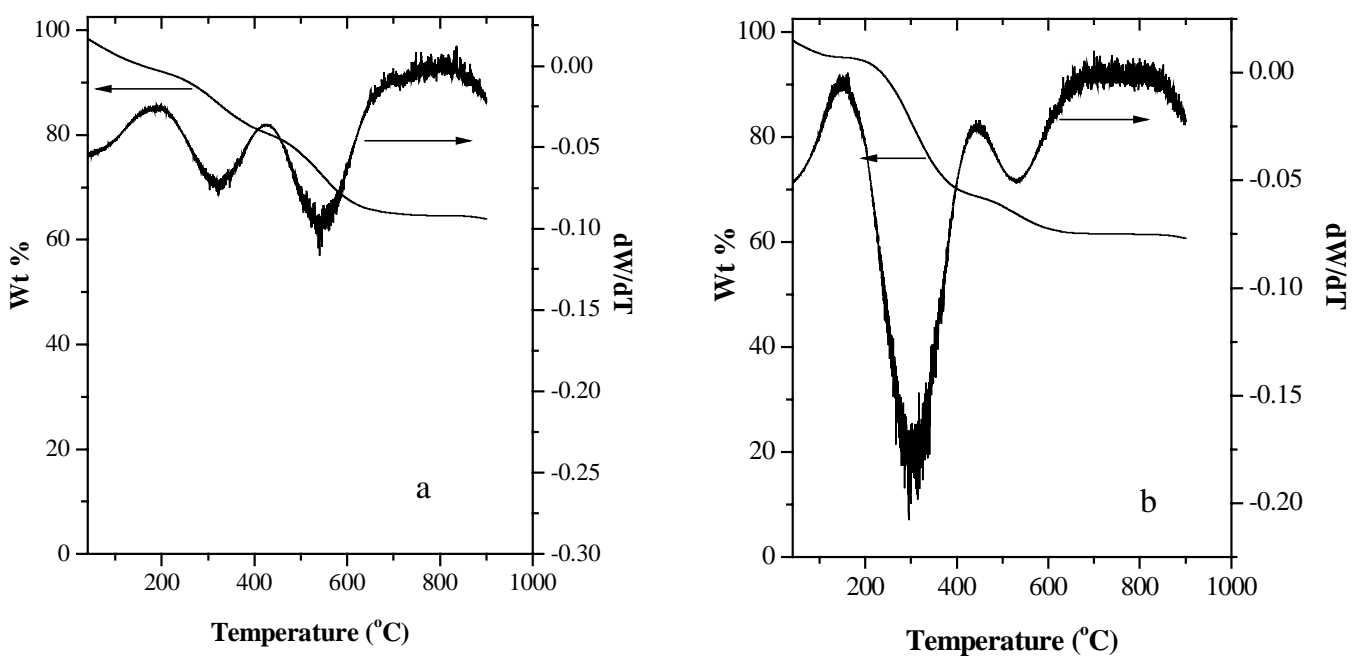

Figure S8. TGA and DTG curves of (a) as-made Si-FDU-18 and (b) Si-FDU-18-HC after hydrothermal re-crystallization treatment of as-made Si-FDU-18. Both pyrolysis processes were conducted in air with a heating rate of $5^{\circ} \mathrm{C} / \mathrm{min}$. 